Gerión. Revista de Historia Antigua

ISSN: 0213-0181

http://dx.doi.org/10.5209/geri.71942

\title{
La excavación arqueológica realizada en 1804 en el anfiteatro de Segobriga. Documentos inéditos conservados en la Real Academia de la Historia (Madrid)
}

\author{
Rosario Cebrián Fernández ${ }^{1}$
}

Recibido: 3 de Noviembre de 2019 / Aceptado: 22 de junio de 2020

Resumen. El fondo documental de la biblioteca de la Real Academia de la Historia conserva el expediente "Antigüedades de Cabeza de Griego" (Biblioteca RAH CAI-CU-9-3941/2), que contiene entre otros la información sobre la excavación arqueológica realizada en 1804 en el anfiteatro de Segobriga por J. F. Martínez Falero. En este artículo se presenta el estudio de la documentación inédita acerca de estos trabajos arqueológicos. Ello ha permitido identificar las áreas excavadas y situarlas en la planimetría del edificio para espectáculos.

Palabras clave: arqueología romana; excavaciones arqueológicas; historiografía; Cabeza de Griego.

\section{[en] The Archaeological Excavation Carried out in 1804 in the Amphitheatre of Segobriga. Unpublished Documents Preserved in the Real Academia de la Historia (Madrid)}

\begin{abstract}
The documentary collection of the Library of the Real Academia de la Historia preserves the dossier "Antigüedades de Cabeza de Griego" (Biblioteca RAH CAI-CU-9-3941/2) detailing the archaeological excavation carried out in 1804 by J. F. Martínez Falero in the Amphitheatre of Segobriga. In this article we present the study of unpublished documentation about these archaeological works, allowing us to identify the excavated areas and place them in the planimetry of the building.

Keywords: Roman Archaeology; Archaeological Excavations; Historiography; Cabeza de Griego.

Sumario: 1. Introducción. 2. Las descripciones y excavaciones anteriores del anfiteatro de Segobriga. Siglos XVI-XVIII. 3. Las excavaciones de Juan Francisco Martínez Falero en 1804. La documentación de la planta del anfiteatro. 4. El estado de conservación del anfiteatro en 1830. Las denuncias de expolio en Segobriga y las medidas adoptadas por la Real Academia de la Historia. 5. La restitución arquitectónica del anfiteatro de Segobriga. Situación y características. 6. Referencias bibliográficas.
\end{abstract}

Cómo citar: Cebrián Fernández, R. (2020): La excavación arqueológica realizada en 1804 en el anfiteatro de Segobriga. Documentos inéditos conservados en la Real Academia de la Historia (Madrid), en Gerión 38/2, 435-457.

\footnotetext{
$1 \quad$ Universidad Complutense de Madrid.

E-mail: marcebri@ucm.es

ORCID: 0000-0002-5560-1191
} 


\section{Introducción}

En la serie "Antigüedades e Inscripciones" del Archivo de la Comisión de Antigüedades de la Real Academia de la Historia se conserva un expediente titulado "Antigüedades de Cabeza del Griego", ${ }^{2}$ de especial relevancia para conocer la actividad arqueológica desarrollada en Segobriga en los primeros años del siglo XIX. Los hallazgos arqueológicos, que se habían producido de forma casual en 1760 en el entorno de Cabeza de Griego (Saelices, Cuenca), marcaron el inicio de una fructífera etapa de trabajos de excavación en el yacimiento arqueológico.

Todo cambió para la historia de la investigación arqueológica de Segobriga un 23 de octubre de 1789, fecha en la que se iniciaron las primeras excavaciones en el lugar exacto donde se había producido aquel hallazgo fortuito de varios fragmentos de la lápida del obispo Sefronio. ${ }^{3}$ Como una auténtica campaña de excavaciones, se registró en un diario cada una de las inscripciones, piezas decoradas y objetos documentados y se realizó el dibujo de la planta y principales alzados del edificio. ${ }^{4} \mathrm{Se}$ había exhumado la denominada basílica visigoda, donde se encontraban enterrados varios de los obispos de la sede episcopal segobrigense documentada por los concilios toledanos entre los años 589 y 693. La popularidad alcanzada por el lugar tras este descubrimiento despertó también el interés por la realización de excavaciones, que prosiguieron en la ciudad romana.

Con lo que ahora conocemos de la topografía antigua de la ciudad, gracias a las excavaciones más o menos continuadas desde mediados del siglo XX, podemos reconocer los edificios, estructuras y zonas donde se llevaron a cabo trabajos arqueológicos a finales del siglo XVIII y durante la siguiente centuria. Estos trabajos aportaron los primeros datos científicos sobre la ciudad romana y visigoda y permitieron situar la antigua Segobriga en la ruinas del cerro de Cabeza de Griego, zanjándose una de las más acérrimas discusiones eruditas de la época. ${ }^{5}$

"Antigüedades de Cabeza del Griego" reúne los documentos de las excavaciones realizadas en el invierno de 1804. El 18 de abril de ese año, Juan Francisco Martínez Falero, abogado residente en Saelices, remitió una carta a Joaquín Juan de Flores y la Barrera, Secretario de la Academia, detallando las excavaciones realizadas en el anfiteatro, criptopórtico junto al teatro y necrópolis visigoda, dirigidas por él. ${ }^{6}$ La serie incluye también la primera denuncia de expolio en Segobriga, que puso a prueba a la Real Academia de la Historia en la adopción de medidas encaminadas a la protección de sus restos arqueológicos. La información pormenorizada contenida en este expediente sobre el anfiteatro se presenta ahora y supone la continuación de los documentos ya publicados, que recogen las noticias de las primeras excavaciones en el yacimiento arqueológico entre los años 1789 y $1790 .^{7}$

\footnotetext{
Biblioteca RAH CAI-CU-9-3941/2.

Sobre las inscripciones visigodas recuperadas en el siglo XVIII en Segobriga, incluida la de Sefronio, puede verse Abascal - Cebrián 2006a, 283-294.

Fernández 1790 .

Almagro Basch 1983, 53-66 y 117-131.

El catálogo de los documentos contenidos en este expediente en Cebrián 2002, 161-166.

Sobre las excavaciones de finales del siglo XVIII en Segobriga, Almagro Basch 1983, 86-112.
} 


\section{Las descripciones y excavaciones anteriores del anfiteatro de Segobriga. Siglos XVI-XVIII}

En 1574 el cronista Ambrosio de Morales identificó, por primera vez, el edificio que se encontraba en la ladera septentrional del cerro de Cabeza de Griego con un anfiteatro al que los pastores llamaban "el Alhondiga", derivado de alholí o granero por la cantidad de trigo quemado que aparecía en su interior. ${ }^{8}$ De su relato se deduce que el edificio era visible, conservándose su fachada norte y distinguiéndose la forma ovalada de su arena.

Contó que tenía planta redonda y que medía más de sesenta pies de diámetro $-c a$. $16,72 \mathrm{~m}-$, aunque esta medida se aleja de las dimensiones generales del anfiteatro -74 m de diámetro máximo-y de la arena-41,40 m de diámetro máximo- por lo que no debió tener ante sus ojos el edificio completo, intuyendo su forma y ofreciendo un diámetro muy inferior al real. En aquella fecha se conservaba en pie al exterior de su fachada norte un edificio preexistente del que hoy solo conocemos un tramo de muro de opus vittatum, de $12 \mathrm{~m}$ de longitud y orientación este-oeste, que fue respetado tras la construcción del anfiteatro, condicionando el trazado de la curva del frente norte y provocando la significativa irregularidad que presenta. Sobre él, Morales indicó "Como estaba en ladera (el anfiteatro), por la parte baxa, para su firmeza, tenía un edificio delgado que le servía de estribo".

La noticia sobre los descubrimientos en Cabeza de Griego de 1760 propició que la Real Academia de la Historia comisionase al académico José Alsinet para que visitase el lugar e informase de los hallazgos. Tras el examen in situ de sus restos, escribió una carta dirigida al Secretario de la Institución, Lorenzo Diéguez, fechada el 26 de octubre de 1765, en la que exponía su dictamen. ${ }^{10}$ En esta carta señaló la existencia del edificio para espectáculos en la ladera norte del cerro, aunque no aportó ningún otro dato: "El seno en forma de anfiteatro, declive hacia el Norte, presenta situación de una decente ciudad". ${ }^{11}$

Las primeras excavaciones en el anfiteatro se llevaron a cabo tras la conclusión de los trabajos que habían exhumado la basílica visigoda. ${ }^{12}$ En el diario de 1790 de aquellas excavaciones, Juan Antonio Fernández ${ }^{13}$ incluyó una descripción minuciosa del edificio y un diseño de su planta, que constituye la primera planimetría conocida del anfiteatro de Segobriga:

Siguiendo unos quatrocientos pasos desde la dicha Yglesia ò Cementerio, acia el medio día, se encuentra con el pie del Cerro, ò monte de Cabeza del Griego, y à

\footnotetext{
Morales 1792 [1574], 100-101. En todas las citas se respeta la puntuación y grafía original.

Morales 1792 [1574], 100.

10 Biblioteca RAH-CU-9-7953-1/3, cuyo texto íntegro fue publicado en el Boletín de la Real Academia de la Historia. Alsinet 1888, 353-356.

11 Alsinet 1888, 353.

12 Sabemos por Capistrano de Moya $(1792,90)$ que en el anfiteatro se realizaron varias excavaciones en el primer semestre de 1790, de manera que la actividad arqueológica de finales de 1789 en la basílica visigoda debió proseguir en la ciudad romana. Al mismo tiempo, conocemos por Fernández (1790, 41-42) que se habían realizado excavaciones también en el anfiteatro y en el criptopórtico adosado al tramo de muralla situado junto al teatro, según se deduce de sus palabras "Hasta aquí llega la relacion de los principales frutos de la Escabacion, los quales, podemos decir, que estàn sin Patria, ni dueño legitimo", aunque no aportó el dato concreto sobre la fecha en la que se llevaron a cabo.

13 Sobre los documentos de Fernández conservados en la Real Academia de la Historia, Abascal 2014.
} 
luego de su subida se descubren las ruinas de un Amphiteatro, que manifiestan bien qual era su forma. Esta construido en el declive septentrional del monte, y por esta parte se vè que la gradería se elevaba mucho; y por la opuesta no era tan alta, siendo regular la supliesen con maderas, à no ser que fuese de edificio que ya no parece. Su figura es ovalada, y el diametro menor de las arenas, ò pavimento del Amphiteatro, mas de sesenta varas. /37/ Por la pared del norte tiene la entrada, ò subida con veinte escalones, à que los antiguos, por la figura llamaban cuneo. Inmediatos à este hay dos fuertes edificios à modo de quartos, ò aposentos con unos arcos en el grueso de las paredes, y era preciso que para comunicarse por ellos se valiesen de escalas portatiles, porque están los arcos, ò conductos mencionados distantes à bastante altura del suelo. Puede ser fuesen calabozos, ò ergástulos para prisiones, ò carceles, y que por medio de cuerdas baxasen à los reos, ò condenados al castigo. Detrás de estas piezas, hay otra mui semejante, con la entrada por las arenas, y aqui pondrían à los que destinaban à ser devorados de las fieras: es reducida, y está debajo de la gradería. A la mano izquierda del cuneo, ò subida, à unas veinte varas de distancia se /38/vè el lugar donde encerraban à las fieras: tiene una salida estrecha al Amphiteatro; y aun se registran los ahugeros donde ponían las trancas, ò barras de hierro para la seguridad en dos grandes postes de roca, ò peña que están à una y otra parte, à diferencia de lo restante de la fabrica que es de piedra, y ladrillos, segun estilo romano. Hallanse calaveras, y huesos de animales extraños, y porciones del enlucido que tenian las paredes de una costra, ò baño de grande consistencia pintado de color rojo con lineas de blanco, y amarillo mui permanentes. Para que mas facilmente se venga en conocimiento de lo referido se propone el siguiente diseño con su explicacion, y medidas. ${ }^{14}$

El anfiteatro segobrigense fue construido al norte de la ciudad, fuera del recinto amurallado y junto a una de las puertas de acceso. Para su construcción se aprovechó la topografía del terreno, apoyándose en la roca natural una buena parte de la gradería sur, mientras la norte se elevó desde sus cimientos con una estructura conformada por tres anillos, que constituye el muro de fachada, el muro del balteus y la primera praecinctio y grada de honor. Entre los dos primeros se situaron muros transversales, que dispusieron de arquillos de comunicación a los que refiere Fernández en su descripción. Por tanto, a finales del siglo XVIII estaba a la vista parte de la fachada norte del edificio incluida una de las puertas de acceso de los espectadores a la gradería, que se realizó a través de una escalera, hoy conservada. Y también se distinguían varias filas de asientos de sillería, tanto en el lado norte como en el sur, la carcer que se abría junto a la porta triumphalis, cuyas paredes interiores conservaban entonces restos de pintura mural de color rojo con líneas blancas y amarillas, y la estancia abovedada situada en el extremo norte del eje menor de la arena (Fig. 1).

Un dato relevante señalado por Fernández está relacionado con la porta triumphalis. Describió y diseñó el muro que la delimitaba por su costa norte, del que dijo estaba construido de piedra y ladrillos, y el pasillo existente en este lateral. Este corredor de acceso a la arena conectaba con el pasillo de comunicación entre esta puerta y la occidental. Una cámara flanqueaba lateralmente dicho pasillo, probablemente destinada a la estabulación de los animales empleados en el espectáculo. El corredor estaba conformado por varios sillares dispuestos

14 Fernández 1790, 36-38. 
verticalmente a los que se anclarían vigas de madera como cerramiento. Fernández detalló incluso los rebajes de sección cuadrangular para la colocación de estas vigas, que aún se conservan hoy (Fig. 2).

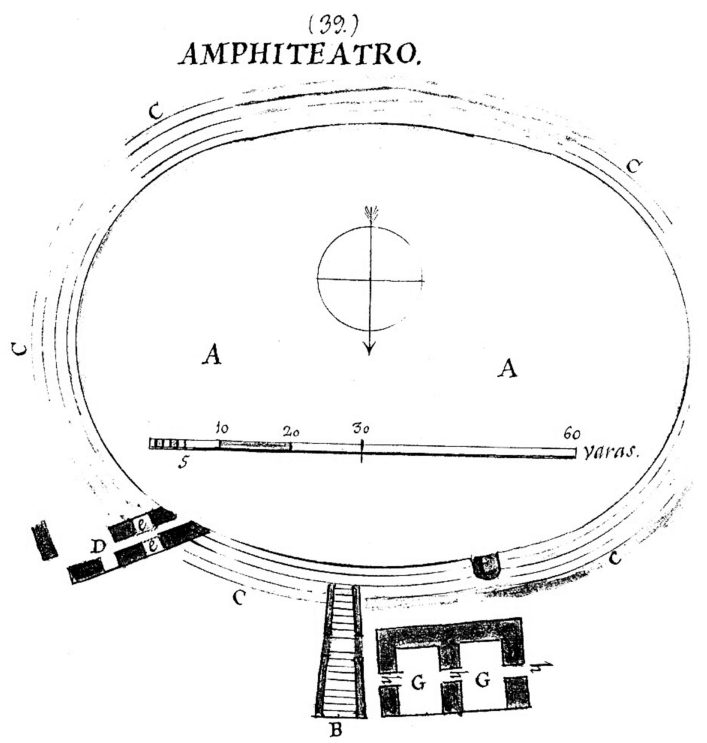

Fig. 1. Planta de los restos conservados del anfiteatro de Segobriga, según Fernández 1790, 39. Leyenda del plano: "AA... arena, pavimento, ò suelo del Amphiteatro. B... Entrada, y escala para subir à ocupar los asientos ò graderias los espectadores. CC\& Porciones de graderias, que aun se mantienen. D... Lugar donde encerraban à las fieras. ee. Peñas, ò rocas de una pieza. F... sitio ò calabozo para los que echaban à las fieras. GG... Edificios, ò piezas que parecen carceles, ò calabozos: hhh. Comunicación de las paredes por medio de arcos".

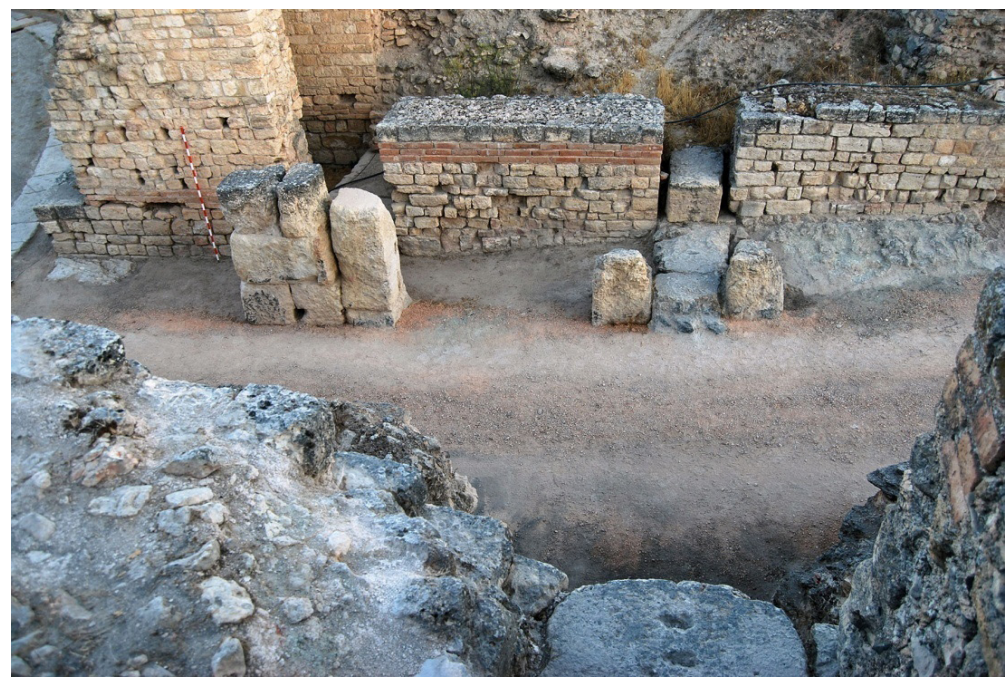

Fig. 2. Vista longitudinal del pasillo existente en la porta triumphalis y alzado del muro de opus vittatum con filas de ladrillos de su lado norte (C R. Cebrián). 
También diseñó en el plano el extremo más septentrional del muro construido con sillares reutilizados de época tardorromana, cimentado sobre el umbral de la porta triumphalis y adosado al estribo del arco de entrada. ${ }^{15}$

A pesar del detalle pormenorizado sobre la situación y estructura constructiva del anfiteatro ofrecida por Fernández, no indicó correctamente las dimensiones de la arena en el plano que realizó, lo que confirma que el edificio no estaba completamente excavado y permanecía enterrado el lado occidental. Supuso una longitud de 73,07 $\mathrm{m}$ en el eje este-oeste y de 51,58 $\mathrm{m}$ en el eje norte-sur, cuando las medidas reales son muy inferiores, de $41,40 \mathrm{~m}$ y $34 \mathrm{~m}$, respectivamente. ${ }^{16}$

Jácome Capistrano de Moya, párroco de la Fuente de Pedro Naharro (Cuenca), en su crónica impresa sobre los descubrimientos de Segobriga hasta marzo de 1790 señaló que el interior del anfiteatro -al que denominó circo- se encontraba terraplenado con vertidos que superaban $\operatorname{los} 5 \mathrm{~m}$ de potencia y que en la zona central de la arena habían sido excavados, pero no se había conseguido llegar al nivel de circulación:

Extramuros de esta poblacion, y cerca de su entrada á la falda Septentrional, se conservan los muros de un espaciosísimo Circo Romano, que estuvo pintado sobre el revoque de la cal, sin otra preparacion: No se ha apurado, si fué teatro ó anfiteatro; porque aunque se han hecho varias tentativas, y en su centro, ó en el medio se ha excavado hasta cinco ó seis varas de profundidad, por ninguna parte se ha llegado al suelo firme, y piso de este edificio. Yo sospecho que los Godos, nada inclinados á las cosas de los Romanos, tiráron á borrar esta memoria de ellos, llenando con todo el escombro, despojos y vasuras de la poblacion este circo; pues no hay inductivo para conducir por otro medio tanta tierra como ha sido necesaria para terraplenar hoya tan grande y profunda como forma el circo, suyos muros, apénas se descubren una vara, estando como están quasi íntegros. Como la poblacion y sus murallas están en sitio dominante, ningun trabajo les costó echar en el circo todos los despojos del pueblo: Segun vestigios nada equívocos, demuestran tuvo este edificio su entrada por el Oriente. ${ }^{17}$

En la misma publicación dio cuenta de los progresos de las excavaciones en el anfiteatro en el segundo trimestre de 1790. De su relato se deduce que su exhumación había proseguido después de que Fernández describiese su planta:

Las excavaciones, por último, se han trasladado al Cerro Cabeza del Griego, de presente, $\mathrm{y}$ en el circo de que tambien se ha hablado, se han hecho algunas catas: toda la haz interior, parece que es de sillería: se han descubierto tres entradas

15 El desmonte del resto del muro tardío (UE 6220) que vio Fernández se llevó a cabo en la campaña de excavaciones del año 2001. Estaba formado por grandes sillares reutilizados, trabados con piedras y barro. El anfiteatro de Segobriga estuvo en uso hasta finales del siglo III, cuando se produjo un incendio evidenciado en las excavaciones de los años 80 del siglo XX a partir del hallazgo de muros calcinados y estratos con restos de fuego (Almagro - Almagro-Gorbea 1997, 82). Tras su abandono, sobre la arena se instaló un barrio de casas y corrales, cuya técnica constructiva a base de sillares reutilizados, principalmente, aconseja una cronología tardía. Sobre la reocupación del anfiteatro, Sánchez-La Fuente 1995, 177-183.

16 Almagro - Almagro-Gorbea 1995, 185.

17 Capistrano de Moya 1792, 70-71. Fue nombrado académico correspondiente el 4 de febrero de 1791 y facilitó la tarea del académico Cornide en 1794 cuando fue comisionado por la Institución para realizar una descripción pormenorizada de los hallazgos que se habían producido unos años antes. 
mirando al Norte. La de enmedio principia al pie de la falda del Cerro; con alguna anchura, sus escalones suben estrechándose en diminucion hasta lo alto de las murallas del circo, donde perseveran quatro ó seis órdenes de graderías, que sirvieron de asiento á los Expectadores: como á unos treinta pasos de aquella entrada, á uno y otro lado se han descubierto las otras dos, que están al piso de la plaza, y area del circo paralelas, por donde se conjetura, que entraban las fieras, pues está ya de manifiesto que es anfiteatro, y siendo, al parecer, el único que se conserva íntegro en España, reputo que deberia promoverse su desmonte, por quien pueda hacerle, y aun reparar las quiebras que tenga para conservar este singular monumento de la antigüedad. ${ }^{18}$

La excavación había continuado en el lado norte del anfiteatro, descubriendo el alto muro de sillares del podium y tres de las puertas de acceso del público situadas en la fachada septentrional. La central ( $2^{\circ}$ vomitorio) con escalera fue descrita por Fernández, pero más tarde se localizaron los vomitoria dispuestos a ambos lados de esta. De las puertas referidas solo se conservaban los muros laterales que habían sido trazados desde sus cimientos, de manera que al desaparecer los tramos de escaleras parecían entradas al nivel de la arena. Así se explica que Capistrano de Moya considerase que el $1^{\circ}$ y $3^{\circ}$ vomitoria sirvieron para el acceso de los animales que participaron en el espectáculo.

La última información con la que contamos sobre el anfiteatro antes de la excavación de 1804 es la descripción realizada por José Cornide en el viaje que realizó comisionado por la Academia en $1794 .{ }^{19}$ Él vio los restos excavados unos años antes, ofreciendo el detalle de las dimensiones de los ladrillos intercalados en su fábrica. Consideró que el anfiteatro estuvo construido dentro del pomerium de la ciudad:

A la derecha de esta (entrada principal de la población), y dentro de la muralla, estaba el anfiteatro que presentaba su frente al norte, segun las reglas que observaban los antiguos en tales edificios. Hoy se halla casi terraplenado; y solo por la parte inferior y por el costado de oriente se descubren dos vomitorios, y algunas de las caveas ó carceles donde se guardaban las fieras. Su entrada principal debia de ser entre mediodia y poniente al plano del camino que baxa de la ciudad; pues así lo proporciona el terreno: su figura era eliptica, su mayor diametro de 70 varas, y el menor de 58 .

Morales le tiene por anfiteatro, aunque supone que el empleo de Director de las mascaras (Magister laruarum que dice se hallaba en una inscripcion) pertenecia á este edificio; siendo así que este empleo supone el de un teatro en Cabeza del Griego; del qual era propio, y no del anfiteatro. La fábrica de este era de mampostería, interpolada con verdugos de gruesos y grandes ladrillos de 19 pulgadas y media de largo por 13 y media de ancho con 3 y medio de grueso, y

18 Capistrano de Moya 1792, 100-101.

19 De aquel viaje, que tuvo lugar entre el 27 de junio y el 15 de julio, redactó una extensa memoria sobre los hallazgos y restos conservados, que fue publicada por la Real Academia de la Historia, Cornide 1799, 71-244. Del viaje a Cabeza de Griego, Cornide escribió dos manuscritos conservados en su biblioteca (Biblioteca RAH Ms. 9-3912, ff. 157-196, y Ms. 9-4130, tomo 37, de la colección del Marqués de Valdeflores). Sobre la figura de Cornide y los diarios de los viajes realizados por España y Portugal conservados en esta Institución, Abascal Cebrián 2009. 
revestida de sillares pequeños; de los quales se descubren todavia algunos, y otros que se han llevado á las poblaciones vecinas. ${ }^{20}$

De aquel viaje, disponemos de un boceto a tinta de la situación de los restos constructivos conservados en Cabeza de Griego dibujado por el arquitecto Melchor de Prado y Mariño, que acompañó a Cornide. En él localizó gran parte del trazado de la muralla, salvo por su costado norte, once cisternas, el anfiteatro, el criptopórtico adosado a la muralla y la ermita dedicada a la Virgen de los Remedios construida sobre las termas monumentales, junto a algunos restos de estructuras en el lugar que ocupa el teatro y otros dispersos por el interior del recinto amurallado. En el dibujo se observa en el centro de la arena del anfiteatro la excavación a la que se refirió Capistrano de Moya. También se aprecia claramente la escalera del $2^{\circ}$ vomitorio y los muros anulares que conformaron la estructura de la gradería norte (Fig. 3).

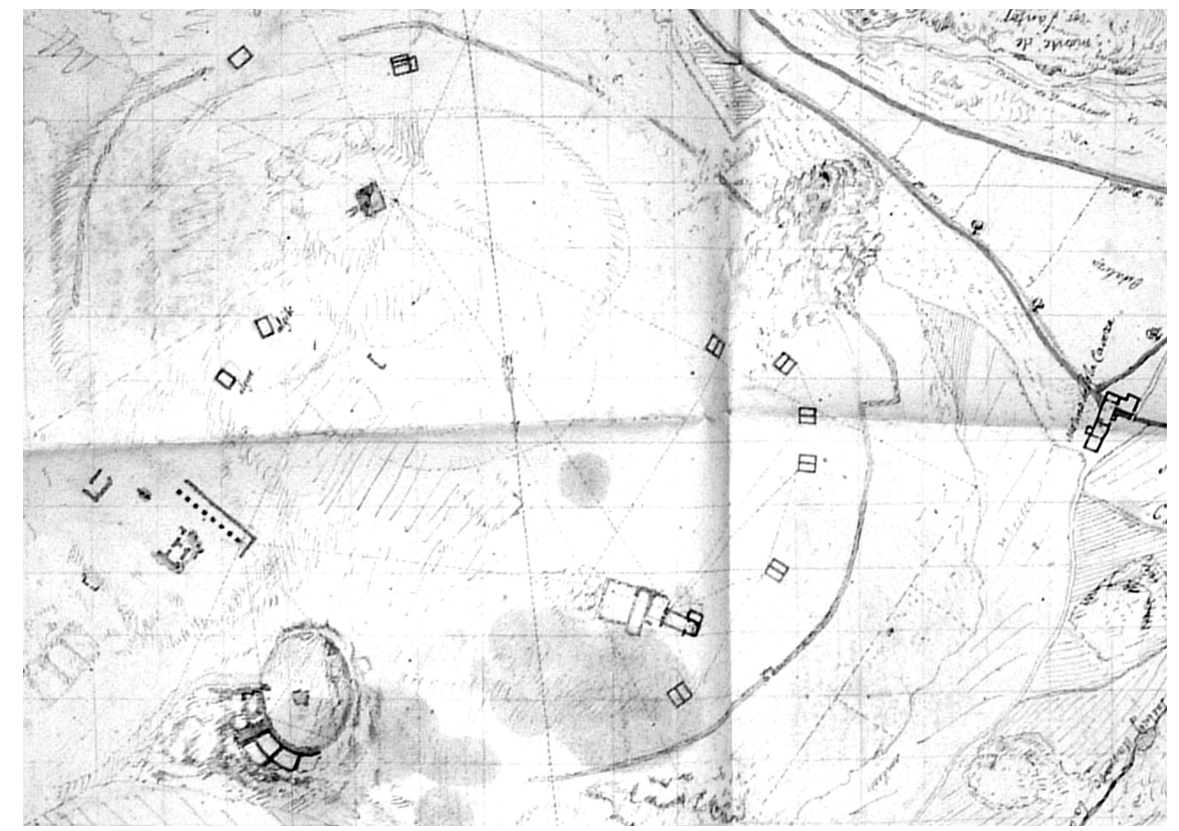

Fig. 3. Boceto del cerro de Cabeza de Griego con la situación de los restos conservados realizado por Melchor de Prado (Biblioteca RAH 9-4130-15) durante el viaje de 1794 con José Cornide y reproducido en grabado por Tomás López Enguídanos, en la crónica del viaje a Segobriga (Cornide 1799, lám. 2).

Sobre estas primeras excavaciones de 1790 en el anfiteatro hablará J. F. Martínez Falero en la carta remitida a la Academia dando cuenta de las excavaciones realizadas en 1804:

El anfiteatro, que en las anteriores escavaciones quedo solamente iniciado, porq $^{\mathrm{e}}$ entonces nada más se descubrio, que uno de sus Vomitorios, dos cabias, o Jaulas para las Fieras, y la direccion del Podio en corta extension por su parte superior,

20 Cornide $1799,172$. 
pedia alguna atencion; Aquel descubrimiento, aunque tan limitado vasto por si solo para llegar a conocer sin duda alguna era Anfiteatro, lo $\mathrm{q}^{\mathrm{e}}$ asta entonces no havia pasado de la esfera de una mera conjetura, pero no fue vastante para saber la dimension de su circulo interior su mas o menos elevacion, calidad de su fabrica, estado de su mas o menos integridad y partes de $\mathrm{q}^{\mathrm{e}}$ se componia: Al paso $\mathrm{q}^{\mathrm{e}}$ la curiosidad anelaba por estos descubrimientos, la mucha tierra $/ 3 /$ y escombros que totalmente lo cubrian servian de obstaculo a la empresa; Determinose sin embargo poner esta en planta con la confianza de una buena direccion, y asi trasladada la escavacion a este parage se a logrado descubrir en la maior parte lo mismo, que se deseaba: ${ }^{21}$

Según él, los trabajos arqueológicos solo habían descubierto parte del podium y $\operatorname{los}$ vomitoria $1^{\circ}, 2^{\circ}$ y $3^{\circ}$ de la gradería norte, aunque conocemos por las noticias ofrecidas por Fernández y Capistrano de Moya que el alcance de las excavaciones fue mayor. Se había exhumado también parte del sistema constructivo de celdillas de la estructura norte, la estancia situada en el eje menor de la arena en el lado septentrional y el pasillo y límite norte de la porta triumphalis. Se lamentó que estos trabajos no habían sido suficientes ni siquiera para conocer las dimensiones totales del edificio para espectáculos, su alzado, sus partes y técnicas constructivas, a la vez que llamó la atención de la gran cantidad de tierra que lo cubría.

\section{Las excavaciones de Juan Francisco Martínez Falero en 1804. La documentación de la planta del anfiteatro}

Las razones que dieron lugar a las excavaciones de 1804 en Segobriga fueron expuestas por J. F. Martínez Falero en aquella carta. Al inicio del texto señaló que el Real Consejo de Castilla había ordenado el 3 de febrero realizar trabajos arqueológicos para dar empleo a los jornaleros de Saelices durante el invierno de ese año y para servir también al conocimiento de sus monumentos. Los trabajos serían financiados con cargo a los recursos propios de la villa y dirigidos por este miembro de la familia Martínez Falero, que tuvo un destacado papel en las excavaciones y protección de los restos del yacimiento arqueológico desde finales del siglo XVIII y durante la primera mitad del XIX.

Las excavaciones se iniciaron el 17 de febrero de 1804 y la elección del lugar donde iban a llevarse a cabo fue convenida con Bernardo Manuel de Cossio, cura de Saelices, y Vicente Martínez Falero. Juntos decidieron primeramente proseguir las excavaciones en el criptopórtico situado junto al teatro, donde ya se habían descubierto varios de los pilares centrales, que sustentaron el pórtico superior de doble galería delimitador por el norte de una plaza situada entre el foro y el teatro. ${ }^{22}$

21 Biblioteca RAH CAI-CU-9/3941-2/2.

22 Sobre el complejo monumental construido en época tiberiana y su evolución cronológica, véase Abascal et alii 2010, 26-30. Fernández (1790, 40-41) había narrado el descubrimiento de ocho de estos pilares y el hallazgo de varias estructuras murarias en su entorno, elaborando su planimetría. Por su parte, Capistrano de Moya (1792, 101-102) indicó que a mediados del año 1790 se habían descubierto otros dos pilares y el tramo de muralla al que se adosó el criptopórtico. 
J. F. Martínez Falero era abogado de los Reales Consejos y residía en Saelices. Había participado en las excavaciones de la basílica visigoda y había sido testigo la tarde del lunes 14 de diciembre de 1789 del hallazgo de los sepulcros de los obispos Sefronio y Nigrino, apareciendo su nombre en el "Acta original del hallazgo de reliquias, firmada por todos los presentes y autentificada por Juan Antonio Fernández". ${ }^{23}$ Era sobrino de V. Martínez Falero, alcalde de Saelices en la fecha en la que se llevaron a cabo aquellas primeras excavaciones en Segobriga. ${ }^{24}$ Sabemos que en octubre de 1790 ocupaba él el cargo de alcalde de la localidad, pues así lo declaró en el proceso abierto por el obispo de Cuenca, Felipe Antonio Solano, sobre los hallazgos de la basílica visigoda y especialmente de los huesos recuperados de los obispos Sefronio y Nigrino. ${ }^{25}$ También lo indicaba el texto de la inscripción, que mandó colocar en la entrada a la cerca construida para proteger los monumentos exhumados de la basílica. ${ }^{26}$ Tío y sobrino fueron nombrados Correspondientes de la Real Academia de la Historia en sesión del 24 de abril de $1795 .{ }^{27}$ En respuesta a la polémica suscitada sobre la situación de la antigua ciudad romana y diócesis visigoda de Segobriga, remitió en 1802 a la Academia una Memoria, que constituye su único trabajo publicado. ${ }^{28}$

23 Biblioteca RAH 11-816-74.

24 En el primer informe sobre las excavaciones en Cabeza del Griego, fechado en Uclés el 14 de diciembre de 1789 y remitido al Conde de Floridablanca (Biblioteca RAH-CU-9-7953-1/10), Antonio Tavira señaló el parentesco entre Vicente y Juan Francisco Martínez Falero y la profesión de este último: “Abogado de mucha y buena instruccion y particular merito".

25 A. D. C., leg. 1519, exp. 1, f. 49: "Sr. Liz. ${ }^{\text {do }}$ D. Juan Fran. ${ }^{\text {co }}$ Martinez Falero, Abogado de los R. ${ }^{\text {s }}$ Consejos y Alcalde Ordinario por S. M., y estado noble de la dicha Villa".

26 El Intendente Real de la provincia de Toledo comunicó por carta, de fecha 1 de julio de 1790, a los Señores Justicia y Junta de Propios de la villa de Saelices, que debía llevarse a cabo la construcción de esa cerca (Cornide 1799, 242). En ella se colocaron varias inscripciones conmemorativas. En la "Segunda Memoria de las excavaciones en Segobriga", redactada por Juan Antonio Fernández el 4 de febrero de 1791, adjuntada en la carta al Obispo de Cuenca, copió el texto en la que aparecía el nombre de J. F. Martínez Falero, como alcalde de la localidad, junto a Diego de Platas Oliva (Biblioteca RAH 9-5597-2). Fue reproducida por Cornide en el "Apéndice IV. Ultimo estado de las excavaciones, y providencias relativas á ella" en su memoria sobre las antigüedades de Cabeza de Griego. El nombre de J. Francisco (Martínez) Falero aparecía también en la inscripción en latín compuesta por el prior de Uclés, Antonio Tavira, que se situó en el arco de entrada al crucero de la basílica visigoda. Sobre el texto de ambas inscripciones, Cornide 1799, 240-241, y Almagro Basch 1983 , 99-100.

27 Memorias de la Real Academia de la Historia IV, 1805, XXXVI. En el tomo V, 1817, LXIX, Vicente y Juan Francisco Martínez Falero seguían apareciendo en el catálogo de los individuos académicos como correspondientes, pero por la información aportada en el tomo VI, 1821, LXVIII, ya habían muerto en aquella fecha: "La Academia ignoraba hasta ahora la (muerte) de dos beneméritos individuos suyos, los Sres. D. Vicente, y D. Francisco Martínez Falero, vecinos de la villa de Sahelices, que fallecieron hace algunos años. La parte que tuvieron estos celosos correspondientes en el descubrimiento de las antigüedades de Cabeza del Griego, y en las diligéncias de la Académia para ilustrarlas, está consignada en la colección de nuestras Memórias". En este sentido, en el borrador de una carta de la Academia a su miembro correspondiente Rafael Isidoro de Hervías de 6 de julio de 1819, en contestación a su comunicación sobre el abandono y expolio de las ruinas de Cabeza de Griego, se sospecha "que han fallecido los Sres. D. Vicente y D. Juan Fr"o. Martinez Falero, vecinos de la V $V^{a}$. de Sahelices, sus individuos correspondientes, por la falta de contestación” (Biblioteca RAH CAICU-9-3941-02/15). Este extremo será confirmado por Hervías el 19 de septiembre de 1819 a la Academia: "han fallecido años hace D. Vicente y D. Juan Fran ${ }^{\text {co. }}$ Martinez Falero" (Biblioteca RAH CAI-CU-9-3941-02/16).

28 Martínez Falero 1805, 1-73. Sobre esta Memoria, el autor solicitó una copia a la Academia por carta de 17 de junio de 1806 (Biblioteca RAH CAI-CU-9-3941-2/4), de la que recibiría doce ejemplares de manos del P. Venancio de Priego, agradeciendo este extremo por otra carta de 29 de junio de ese año (Biblioteca RAH CAICU-9-3941-2/6). 
La breve correspondencia que mantuvo con la Academia abarca el período 1804$1806 .{ }^{29} \mathrm{El}$ documento más antiguo es la carta en la que detalló el área excavada en el anfiteatro, aunque la redactó cuando los trabajos arqueológicos proseguían en el edificio:

Su figura es oval, el mayor diametro de su circulo interior lo es de 55 vars $^{\mathrm{s}}$ y su menor de 47; su fabrica es de silleria tosca con algunas fajas de ladrillos; su entrada principal, y unica a su pabimento interior la tiene al lado del oriente; $\mathrm{Al}$ circulo del Podio, y a la distancia de vara, y media le acompaña otro circulo de sillares grandes, y gruesos, que servia para preservar el primero, de que pudiese ser acometido por las Fieras, siendo la altura de aquel por la parte interior de ambos circulos de tres varas, y tres quartas, y la de este de dos, y media; Dentro de estos dos circulos, y vajo de la escalera, o vomitorio, que esta a la parte del septentrion se a encontrado una Alcantarilla de piedra de sillería de vastante longitud, $\mathrm{q}^{\mathrm{e}}$ serviria para recivir, y dar salida a las immundicias de los espectadores; tambien ai acia la misma parte septentrional dos oficinas, sin otra salida que al intermedio de dhos. circulos, y al nivel de su pavimento, las quales parecen no podian tener otro uso que el de canceles para los Reos $\mathrm{q}^{\mathrm{e}}$. destinaban para las Fieras; Ai para estar descuviertas, aunq ${ }^{\mathrm{e}}$ no limpias de todo, quatro Jaulas, y iniciadas asta el numero de otras /4/ seis; estas Jaulas se hallan unidas entre si, aunque con las separaciones de gruesos muros, que al mismo tiempo servian para sostener el edificio por aquella parte del septentrion, pues lo demas se alla resguardado por el mismo cerro, en cuia falda se alla edificado; en estas paredes o muros ai Arcos de comunicacion de las unas a las otras, por lo $\mathrm{q}^{\mathrm{e}}$ puesto algun madero podia facilmente instigarse y enfurecerse a las Fieras al tiempo de su salida al Anfiteatro: La $\mathrm{q}^{\mathrm{e}}$ tenían a este dhas. Jaulas pasaba vaxo el pavimento de dhos. dos circulos, pues el de aquel le escede en profundidad mas de dos varas: A la dha. parte del Norte ademas del dho. vomitorio descubierto, ai otros dos iniciados, y por ellos se subia, y vaxaba desde las partes vajas de la Ciudad a las Gradas, que por esta parte estan enteramente destruidas: A la del Poniente, y frente de la entrada del Oriente se manifiesta tambien iniciado otro vomitorio de descenso a las mismas gradas para el uso de los $\mathrm{q}^{\mathrm{e}}$ havitaban las partes altas de la Ciudad: A la mano siniestra de dha. entrada principal del oriente ai una oficina enteramente arruinada, el qual se estendia asta el circulo interior, o varrera: Confin con esta oficina arruinada se alla al pie de las Gradas, $q^{\mathrm{e}}$ permanecen integras en este parage, y sobre dhos. dos circulos un lugar distinguido con baldosas de piedra en su Pavimento, cuia latitud es /5/ de vara, y media, sin $\mathrm{q}^{\mathrm{e}}$ asta haora se aia depurado su longitud, en el qual concurren todas las circunstancias, que señalan los Antiquarios para reputarlo por aquel que toman los senadores, o Decuriones para la mejor vista de los espectaculos: Las gradas descubiertas, y que continuan descuvriendose por este paraje son de piedra silleria toscamente labradas principian sobre el muro del Podio, y finalizan asta componer el numero de cinco, su altura y planicie es de mas de media vara: Estas gradas se allan con separacion de una escalera estrecha, que los Antiquarios llaman Cuneo, y servia para la suvida, y va a dar a las mismas gradas, sin que huviese necesidad de incomodar a los espectadores: La precincion que era un lugar, o camino desembarazado para dirijirse a estos cuneos esta tambien manifiesta en la parte

29 Cebrián 2002, 161, y Abascal - Cebrián 2006b, 341. 
superior de las gradas, y las cathedras, o lugares destinados $\mathrm{p}^{\mathrm{a}}$ las mugeres que confinaban con la prencincion, y muro exterior se allan enteramente arruinadas. Luego que finalice la escavacion que por limitada a la temporada de invierno sera corta su duracion remitire a esa $\mathrm{R}^{1}$. Academia un diseño esapto con todas sus dimensiones, para $\mathrm{q}^{\mathrm{e}}$ en ella se conserve y perpetue la memo- /6/ ria de este tan particular descubrimiento, $\mathrm{q}^{\mathrm{e}}$ por serlo de un monumento, que aun permanece integro en su maior parte, a pesar de la injuria de los tiempos y tener el merito de ser ia el unico que de su clase nos a quedado de la antiguedad no dexara de ser siempre apreciable, y de la maior recomendacion. ${ }^{30}$

J. F. Martínez Falero comenzó describiendo la planta del edificio y su técnica constructiva. El anfiteatro presentaba planta oval y señaló el uso de sillería tosca para referirse a los lienzos de opus vittatum, realizados con piedras escuadradas de pequeño y mediano tamaño y de tosca labra, es decir, trabajados a golpe de ascia y sin pulir. En estos lienzos de vittatum se intercalan tres hiladas de ladrillo utilizadas como fajas niveladoras en su construcción, que indicó también. Según él, solo existió una entrada directa desde el exterior a la arena, la porta triumphalis, aunque tuvo otra al oeste, que no sería excavada hasta los trabajos de Pelayo Quintero en 1892. ${ }^{31}$

Las medidas que ofrece del anfiteatro están expresadas en varas castellanas. ${ }^{32} \mathrm{Su}$ comparación con las dimensiones aportadas por la fotogrametría aérea realizada en el marco de los trabajos de excavación, consolidación y restauración del edificio a finales de los años 80 del siglo XX apunta a la idea de que el muro del podium seguía sin excavarse en su totalidad. (Fig. 4).

\begin{tabular}{|c|c|c|}
\hline Dimensiones & J. F. Martinez Falero (1804) & $\begin{array}{l}\text { A. Almagro y M. Almagro- } \\
\text { Gorbea (1995) }\end{array}$ \\
\hline longitud arena $\mathrm{E}-\mathrm{W}$ & 55 varas $=45,92 \mathrm{~m}$ & $41,40 \mathrm{~m}$ \\
\hline longitud arena $\mathrm{N}-\mathrm{S}$ & 47 varas $=39,24 \mathrm{~m}$ & $34 \mathrm{~m}$ \\
\hline $\begin{array}{l}\text { anchura pasillo de servicio } \\
\text { lado } \mathrm{N}\end{array}$ & 1,5 varas $=1,25 \mathrm{~m}$ & $1,45 / 0,73 \mathrm{~m}$ \\
\hline altura podium & 3 varas y 3 cuartas $=3,12 \mathrm{~m}$ & $3,10 / 3,15 \mathrm{~m}$ \\
\hline $\begin{array}{l}\text { altura muro cimentación } 1^{\text {a }} \\
\text { praecinctio y grada de } \\
\text { honor en } \mathrm{N}\end{array}$ & 2,5 varas $=1,25 \mathrm{~m}$ & $1,96 \mathrm{~m}$ \\
\hline anchura grada de honor & 1,5 varas $=1,25 \mathrm{~m}$ & $1,40 \mathrm{~m}$ \\
\hline altura y anchura gradas & más de 0,5 varas $=$ más de 41,7 & $0,60 / 0,40 \mathrm{~m}$ \\
\hline
\end{tabular}

Fig. 4. Cuadro comparativo de las dimensiones del anfiteatro proporcionadas por J. F. Martínez Falero en 1804 y las publicadas por Almagro y Almagro-Gorbea en 1995.

Biblioteca RAH CAI-CU-9-3941-02/2.

Quintero - Paris 1902, 252-254, y Quintero 1913, 98.

Sobre la evolución cronológica de la vara castellana como medida de longitud y su equivalencia en metros, puede verse Maier 2005, 49-51. 
Los trabajos arqueológicos de 1804 se centraron en el lado norte del anfiteatro. Se excavó parte del corredor de servicio que unía las dos puertas de acceso a la arena. Por las indicaciones que señala en su descripción, se localizó el tramo del muro del podium oriental, hoy desaparecido, ya que menciona que cerca se encontró el canal de desagüe que atravesaba la arena en dirección este-oeste y sacaba las aguas pluviales del anfiteatro por debajo del $2^{\circ}$ vomitorio. Las excavaciones prosiguieron con la exhumación de un total de diez celdillas comunicadas por arcos de la estructura constructiva de la gradería norte, de las cuales dos ya habían sido descubiertas a principios de 1790. También mencionó la estancia situada en el eje menor de la arena y la carcer contigua a la porta triumphalis, ambas exhumadas en las excavaciones de finales del siglo XVIII. Aledaña a esta carcer, se hallaron la $1^{\circ}$ praecinctio y la grada de honor, pavimentadas con losas de piedra, y se descubrieron cinco de las siete filas de asientos con las que contó la imma cavea. Desconocemos qué sectores o cunei se excavaron, pero es posible pensar que fuesen los más cercanos a la porta triumphalis por los detalles que proporciona. Las excavaciones en esta zona documentaron también una de las escaleras radiales ubicadas en la imma cavea para el acomodo de los espectadores y la $2^{\mathrm{a}}$ praecinctio, que recorría la parte alta de esta cávea. De la summa cavea indicó solo que se encontraba arruinada. Finalmente, en relación a los accesos del público desde el exterior señaló que por la parte norte se encontraban tres accesos $-1^{\circ}, 2^{\circ}$ y $3^{\circ}$ vomitorio- y que por el lado sur había uno junto a la porta triumphalis, en el que habían comenzado los trabajos de excavación.

Al concluir el relato sobre las excavaciones en curso en el anfiteatro comunicó a la Academia que tenía intención de remitir una planta con indicación de todas sus dimensiones en el momento en que terminasen los trabajos arqueológicos. Y ponía a disposición de la institución las 23 monedas halladas en su excavación:

Entre las del Anfiteatro se an hallado una moneda Bastulo Fenicia de mediano modulo, seis de Emperadores tambien de mediano modulo, y de estas son tres de Segobriga de las mas comunes, y de un mismo cuño, y diez y seis de pequeño modulo consulares, todas de cobre, las $\mathrm{q}^{\mathrm{e}}$ con las anteriores ofrezco a la disposicion de la $\mathrm{R}^{1}$. Academia. ${ }^{33}$

La carta de J. F. Martínez Falero fue vista por la Academia en su sesión de 20 de abril de 1804, acordando su contestación, dándole las gracias y aceptando el ofrecimiento de remisión de las monedas y de la planimetría del anfiteatro y del cementerio visigodo. ${ }^{34}$ No llegó a entregar los dibujos comprometidos pero si remitió las monedas. La relación de las 44 monedas enviadas por él a la Academia fue realizada por José Antonio Conde en 1805, pasando a formar parte de la colección numismática del Gabinete de Antigüedades. ${ }^{35}$

No volverían a realizarse excavaciones en el anfiteatro hasta finales del siglo XIX. En 1892 Quintero se hizo cargo de los trabajos arqueológicos financiados por

33 Biblioteca RAH CAI-CU-9-3941-02/2.

34 Biblioteca RAH CAI-CU-9-3941-2/4. Borrador de la carta de la Academia a Juan Francisco Martínez Falero, de 24 de abril de 1804, aceptando la entrega de las monedas descubiertas y los planos del anfiteatro y la necrópolis visigoda.

35 Abascal et alii 2008, 37. El documento con el listado de las monedas se conserva en la Academia con la signatura GN 1805-1(3). 
el inglés Robert Laurie Thomson en Cabeza de Griego, que se prolongaron durante tres meses. ${ }^{36}$ De la breve reseña publicada sobre los hallazgos en el edificio para espectáculos se deduce que se trabajó junto a la puerta oeste de acceso a la arena, donde se llevó a cabo la excavación de una zanja profunda, localizando la carcer contigua al corredor de servicio. Conservaba un pavimento de ladrillos romboidales y restos de la pintura mural de color rojo de sus paredes, descubriéndose restos óseos de animales y una moneda de oro de Recaredo. ${ }^{37}$

Las excavaciones de finales del siglo XVIII y la siguiente centuria habían dejado al descubierto gran parte de la estructura norte de la gradería septentrional y el sector más oriental de la sur. Sus restos acabarían por cubrirse definitivamente de tierra hasta prácticamente desaparecer cualquier evidencia del edificio en la falda de la colina (Fig. 5).

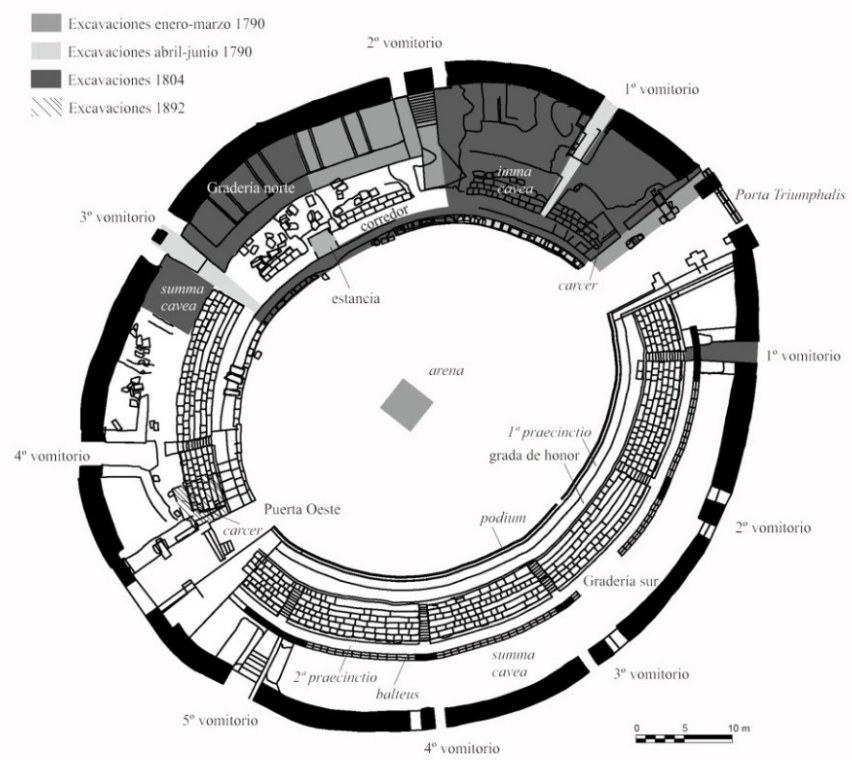

Fig. 5. Planta del anfiteatro con indicación de las áreas excavadas durante los siglos XVIII y XIX y la denominación de sus partes (C) I. Hortelano).

\section{El estado de conservación del anfiteatro en 1830. Las denuncias de expolio en Segobriga y las medidas adoptadas por la Real Academia de la Historia}

La primera denuncia de expolio de los restos arqueológicos de Segobriga llegó a la Academia en 1817. Una carta fechada el 5 de enero de ese año por el alcalde de Saelices, Juan Plácido Martínez Falero, informaba de la extracción de "lapidas y ladrillos" del anfiteatro por una veintena de hombres provistos de picos y azadones, lo que le llevaba a solicitar la remisión de algún documento donde se recogiese la obligación de las Justicias de contener este tipo de atentados con la finalidad 
de exponerlo en el Ayuntamiento de la localidad para que nadie pudiese alegar desconocimiento. ${ }^{38}$

La Sala de Antigüedades de la Academia había elaborado una "Instrucción sobre el modo en el que se recojan, conserven y guarden los monumentos antiguos descubiertos o que se descubriesen en el Reino" por encargo de la Secretaría de Estado. ${ }^{39}$ La Real Cédula sería promulgada el 6 de julio de 1803 y anexada a la Novísima Recopilación de las Leyes de España, sancionada por Carlos IV en 1805. La contestación de la Academia al alcalde de Saelices recordaba esta normativa y, en especial, su capítulo $7^{\circ}$ :

Generalmente las Justicias de todos los pueblos cuidarán de que nadie destruya ni maltrate los monumentos descubiertos, ó que se descubrieren, puesto que tanto interesan al honor, antigüedad y nombre de los pueblos mismos; tomando las providencias convenientes para que asi se verifique. Lo mismo practicarán en los edificios antiguos, que hoy existen en algunos pueblos y despoblados, sin permitir que se derriben ni toquen sus materiales para ningun fin, antes bien cuidarán de que se conserven; y en el caso de amenazar próxima ruina lo pondrán en noticia de la Academia, por medio de su Secretario, á efecto de que este toma las providencias necesarias para su conservacion. ${ }^{40}$

Un año más tarde, la situación en el yacimiento continuaba igual, por lo que el Secretario de la Academia, Diego Clemencín, optó por informar al Secretario de Estado para que interviniese. ${ }^{41}$ Como consecuencia se transmitió una circular, de fecha 2 de octubre de 1818, relativa a la conservación de los monumentos antiguos, "expedida a la Sala de Alcaldes de la Real Casa y Corte, Chancillerías y Audiencias Reales, Corregidores, Gobernadores, Alcaldes mayores y demás Justicias del reino". ${ }^{42}$

La Real Orden formada ante el deterioro que padecían los monumentos de Segobriga propició una intensificación de la labor de la Sala de Antigüedades de la

\footnotetext{
Biblioteca RAH CAI-CU-9-3941-2/7.
}

Maier 2003, 439-473.

40 RAH GA-1803-1/2. El borrador de la carta de la Academia remitida a Juan Plácido Martínez Falero, fechada 31 de enero de 1817, en Biblioteca RAH CAI-CU-9-3941-2/8.

41 Biblioteca RAH CAI-CU-9-3941-2/12. La correspondencia con la Academia en el período 1818-1820 en relación al expolio de los restos de Segobriga fue mantenida por el ya citado Hervías (cf. n. 27), arcediano de Guadalajara en Toledo y correspondiente de la Academia desde el 12 de junio de 1818 (Memorias de la Real Academia de la Historia VII 1832, XLI), que dio cuenta de los saqueos en la basílica visigoda. También Juan José Martínez Falero, hijo de Juan Plácido - que ya había fallecido-, escribió dos cartas a la Academia sobre este asunto. En una de ellas, fechada el 8 de diciembre de 1819, daba cuenta de "el quebranto tan considerable que, por varios vecinos de este pueblo, han padecido las ruinas descubiertas de Cabeza del Griego, pues no haviendose contentado en robar varias lapidas que alli se encerraban, han pasado a derribar las fabricas de los edificios mas principales, como es el de el anfiteatro, y portico, para extraer los ladrillos de que estaban interpoladas: estos fragmentos se conservan en las casas de los vecinos que los han extraido" (Biblioteca RAH CAI-CU-9-3941-2/18).

42 Biblioteca RAH CAI-CU-9-3941-2/13. Facsímil de la Real Orden de 2 de octubre de 1818 relativa a la conservación de los monumentos antiguos. El Consejo acordó su cumplimiento y la circuló a las justicias. La Academia, por su parte, remitió varios ejemplares a sus individuos correspondientes con la finalidad de que promoviesen su cumplimiento en las diferentes provincias, siendo consciente de que en Saelices se había desobedecido la Real Orden dictada por S. M. el 10 de septiembre de 1817, que obligaba al Ayuntamiento a reparar la cerca construida al término de las excavaciones realizadas en la basílica visigoda para evitar la extracción de antigüedades. 
Academia en lo referente a la inspección del patrimonio. En 1828 Valentín de Pinilla, Escribano de Cámara y de Gobierno del Supremo Consejo de Castilla, dio traslado a la Academia de la "exposicion decretada y oficio" del Intendente de Cuenca, Joaquín Manuel del Hierro, a la Justicia y Ayuntamiento de Saelices de fecha 27 de noviembre de 1827, para que informasen sobre el estado de la antigüedades de Cabeza de Griego. ${ }^{43}$

Por la contestación del Ayuntamiento sabemos que el anfiteatro permanecía descubierto en la parte superior de su gradería (norte) y la arena seguía cubierta por vertidos de tierra. El edificio era objeto de expolio al encontrarse abierto y sin ninguna cerca que impidiese el paso. Por ello, el municipio planteó la posibilidad de "desmontar el anfiteatro y cercarlo de manera que no sea hollado en lo sucesivo ni por los ganados que pastan en aquella dehesa ni por otras personas", aunque la Academia aconsejaría finalmente al Ministerio de Hacienda vallar el anfiteatro y colocar una puerta, dejando para más adelante el desmonte del edificio "tanto más cuanto hallándose en su mayor parte cubierta de escombros, no se aventura en el intermedio su conservación". ${ }^{44}$

En 1830, Jerónimo Martínez Falero, abogado y vecino de Saelices, tras ser nombrado correspondiente de la Academia ${ }^{45}$ elaboró una "Memoria sobre el estado en que se hallan las ruinas de Cabeza de Griego, sitas en término de la villa de Saelices". ${ }^{46}$ En ella, una demoledora frase expresaba con mucha franqueza la situación real de los restos: "el tiempo y los elementos no han causado tanto estrago en el enorme espacio de diez siglos y medio como los hombres de nuestra edad en poco más de veinte años". Señaló que para la construcción en 1822 de los baños de Fuencaliente se habían empleado sillares, losas y ladrillos procedentes del anfiteatro por parte del contratista de la obra, previa autorización del Intendente de la provincia. ${ }^{47}$

La Comisión de Antigüedades de la Academia emitió un informe el 5 de noviembre de 1830, tras examinar aquella Memoria en la sesión del 22 de octubre, en el que

43 Biblioteca RAH CAI-CU-9-3941-2/23.

44 Biblioteca RAH CAI-CU-9-3941-2/24. Borrador de un oficio de la Academia al Secretario de Estado, Manuel González Salmerón, señalando la situación en la que se encuentran los restos excavados de Cabeza de Griego, fechado el 6 de abril de 1828 .

45 Biblioteca RAH CAI-CU-9-3941-2/25. Oficio de remisión de la memoria sobre el estado de las antigüedades existentes en Cabeza de Griego, a la vez que agradece el nombramiento de académico correspondiente. Saelices, a 2 de agosto de 1830. La Academia había estado buscando a alguna persona instruida y aficionada a las antigüedades, que viviese cerca de Cabeza de Griego, para ser nombrado académico correspondiente y así paliar el estado de abandono de sus restos, una vez que fehacientemente conocía que V. Martínez Falero y J. F. Martínez Falero habían fallecido. Así, en la Junta de la Academia del 2 de julio de 1819 se acordó encargar al ya mencionado Hervías esta gestión (Biblioteca RAH CAI-CU-9-3941/2/15).

46 Biblioteca RAH CAI-CU-9-3941/2/26. En las Memorias de la Real Academia de la Historia VII, 1832, XVIIXVIII, se recoge la situación de abandono y expolio en el que se encontraban los restos de Cabeza de Griego hacia 1830 .

47 Los baños de Fuencaliente, de aguas ferruginosas indicadas para los tratamientos de reuma, se sitúan a menos de $1 \mathrm{~km}$ al sureste de Segobriga, junto al río Gigüela. La provincia de Cuenca contaba en el siglo XIX con dos manantiales de aguas minero-medicinales, los baños de Fuencaliente y los de Solán. En la sesión de Cortes del día 18 de enero de 1837 Jerónimo Martínez Falero, diputado en las Cortes Constituyentes de 1836 a 1837 y de 1854 a 1857, formó parte de la comisión que promovió una proposición de ley para suprimir las dotaciones de los médicos de baños con fondos del tesoro, señalando que en Fuencaliente solo existía una poza abierta en la tierra y que no contaba con albergue para los enfermos, aunque dotado de un médico con 8.000 reales. Consideraba, y así lo expuso, que sería mejor que se habilitaran estos establecimientos para su uso por los enfermos antes de tener médicos (Sesiones 1837, 172-178). 
se adoptaban una serie de medidas encaminadas a la conservación de los restos arqueológicos de Segobriga, del que se dio traslado a J. Martínez Falero. Entre ellas, se le proponía para que vigilase que no se extrajesen ni mutilasen antigüedades del lugar, a la vez que delimitase el área con monumentos, que además se comunicasen al Ministro de Estado los expolios, se solicitase dinero al Ministro de Hacienda para reparar y mantener intactos los restos que aún no habían sido saqueados y, finalmente, se prohibía la extracción de materiales. ${ }^{48}$

La correspondencia de J. Martínez Falero con la Academia terminará en diciembre de 1830, cuando escribió una carta a Clemencín ofreciendo su mecenazgo en Cabeza de Griego para atender a la conservación de lo descubierto. ${ }^{49}$

El aspecto general del anfiteatro de Segobriga con anterioridad a la realización de las primeras campañas de excavaciones modernas, dirigidas por Gaspar de la Chica entre 1953 y 1955, se aprecia en una fotografía aérea tomada en 1941. Prácticamente todo el edificio se encontraba cubierto de tierra y surcado de diversas zanjas de expolio abiertas para el saqueo de sus materiales, algunas de las cuales debieron iniciarse pocos años después de las excavaciones de 1804, según se desprende de la información aportada por la documentación conservada en la Academia (Fig. 6).

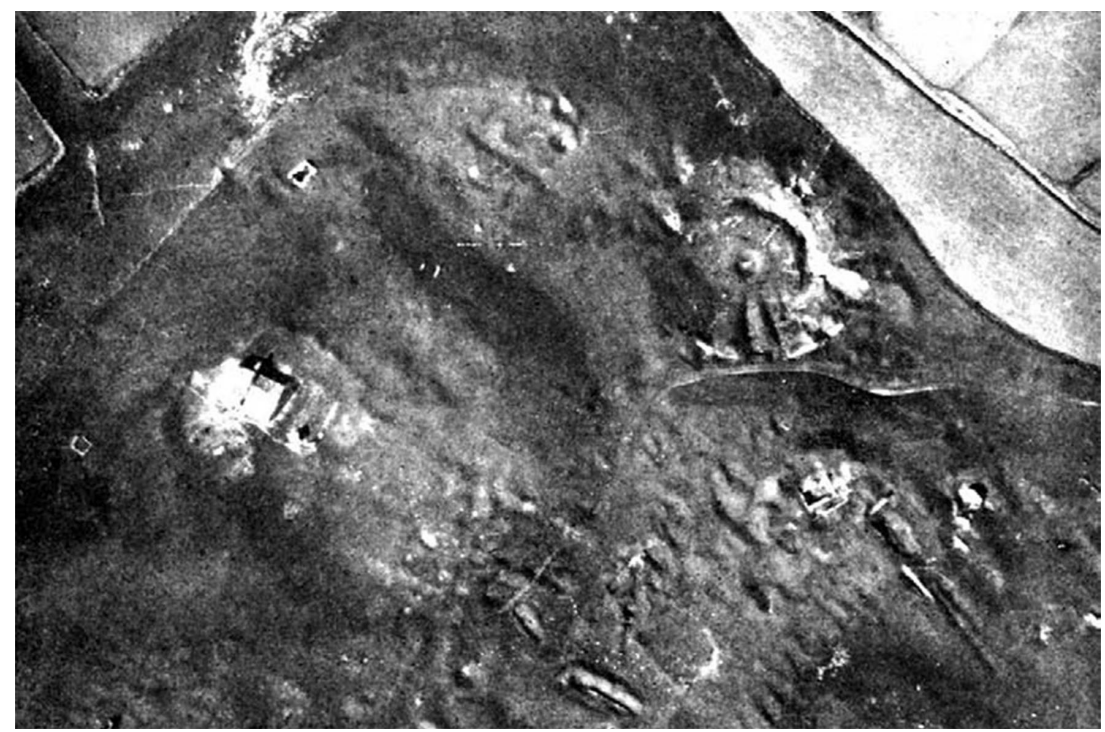

Fig. 6. Vista área de Segobriga en 1941 y estado en el que se encontraban los restos del anfiteatro (Almagro Basch 1943, Lám. II).

\section{La restitución arquitectónica del anfiteatro de Segobriga. Situación y características}

Las excavaciones modernas en el anfiteatro se iniciaron en la década de los años 50 del siglo XX, cuando De la Chica realizó labores de desescombro en el graderío sur y en

\footnotetext{
48 Biblioteca RAH CAI-CU-9-3941/2/27. El informe de la Comisión de Antigüedades fue firmado por Antonio Ranz Romanillos, Antonio Siles y Miguel Salvá.

49 Biblioteca RAH CAI-CU-9-3941/2/29.
} 
el acceso occidental a la arena, dejando visibles las estructuras de reocupación tardía sobre la pista junto al acopio de sillares recuperados en la intervención arqueológica. La posterior excavación, consolidación y restauración del edificio se prolongó a lo largo de distintas fases entre 1972 y 1986, que pusieron al descubierto la totalidad de sus restos. ${ }^{50}$ La última intervención en el anfiteatro se realizó en el período 2011-2013 en el marco de un proyecto de consolidación y adecuación de la cavea sur, con cargo al 1\% del Ministerio de Fomento - Junta de Comunidades de Castilla-La Mancha, que ha permitido precisar el sistema de accesos del público desde el exterior.

El anfiteatro segobrigense se construyó a 100 metros del teatro y flanqueando por el costado occidental la que fue la entrada principal a la ciudad desde época augustea. Aprovechó completamente la topografía existente en el área elegida para su edificación, insertándose en una vaguada natural del terreno por la que desaguaba el interior del espacio urbano a través de una cloaca con salida en la muralla.

Sus dimensiones máximas son $74 \mathrm{~m}$ de longitud y 66,20 $\mathrm{m}$ de anchura, con una superficie en la arena que alcanzó los $1.377 \mathrm{~m}^{2}$. Estructuralmente está construido en dos mitades bien diferenciadas. Mientras la sur se adosa a la ladera del cerro y está excavada parcialmente en la roca, correspondiendo a la disposición en falda de colina definida por Jean-Claude Golvin, ${ }^{51}$ la norte se eleva desde sus cimientos con una estructura adaptada por tres anillos, que forman el muro de fachada, el del balteus y la primera praecinctio y grada de honor (Fig. 7).

El espacio entre el muro de fachada y el que sustenta el balteus se dividió mediante 16 muros transversales y se rellenó de greda con cal hasta alcanzar la altura de la arena. Esa estructura de muros radiales presenta arquillos de comunicación entre celdillas de $0,80 \mathrm{~m}$ de luz y $2,10 \mathrm{~m}$ de altura. Su función se relaciona con el paso de los trabajadores durante su construcción, pues quedaron incomunicadas posteriormente con el exterior. Durante su excavación se documentaron rellenos de tierra con mucha ceniza, lo que llevó a plantear su uso con el fin de aligerar las presiones que habrían de ejercer sobre los muros exteriores. ${ }^{52} \mathrm{Sin}$ embargo, es posible que no se trate de rellenos constructivos, sino de niveles de amortización o destrucción, tomando en consideración sus características físicas, que recuerdan más a los niveles de reocupación y silos documentados en otras zonas del yacimiento arqueológico que a terraplenes. Así tendría sentido la hipótesis planteada por Golvin, el cual considera que en la zona alta de la gradería norte el macizado debió ser precisamente sustituido por una estructura ligera y estática compuesta de muros radiales y bóvedas encofradas que permitió evitar los empujes excesivos sobre su fachada exterior. ${ }^{53}$

50 El análisis de la estructura constructiva, dimensiones y funcionalidad arquitectónica del anfiteatro se debe al arquitecto A. Almagro y al arqueólogo M. Almagro-Gorbea, que fue presentada al congreso internacional sobre anfiteatros de Hispania celebrado en Mérida en 1992 (Almagro - Almagro-Gorbea 1995, 139-164). Previamente, Almagro-Gorbea $(1990,207-218)$ trató los datos aportados por las excavaciones de M. Almagro Basch en el anfiteatro, el cual había llevado a cabo la primera descripción del edificio para espectáculos en la guía del yacimiento sin que hubiesen concluido sus excavaciones (Almagro Basch 1984a, 67-78). Este último publicó también los fragmentos de las inscripciones monumentales recuperadas en el edificio entre los años 1973 y 1977 (Almagro Basch 1984b, 157-161, n 45-47), que serían tratadas por G. Alföldy (1987, 80-81) unos años más tarde. Los últimos hallazgos epigráficos vinculados con la construcción y uso del anfiteatro en Cebrián 2020, 179-181.

51 Golvin 1988, 407, pl. LXX, 3.

52 Almagro - Almagro-Gorbea 1995, 145.

53 Golvin 1988, 119. 


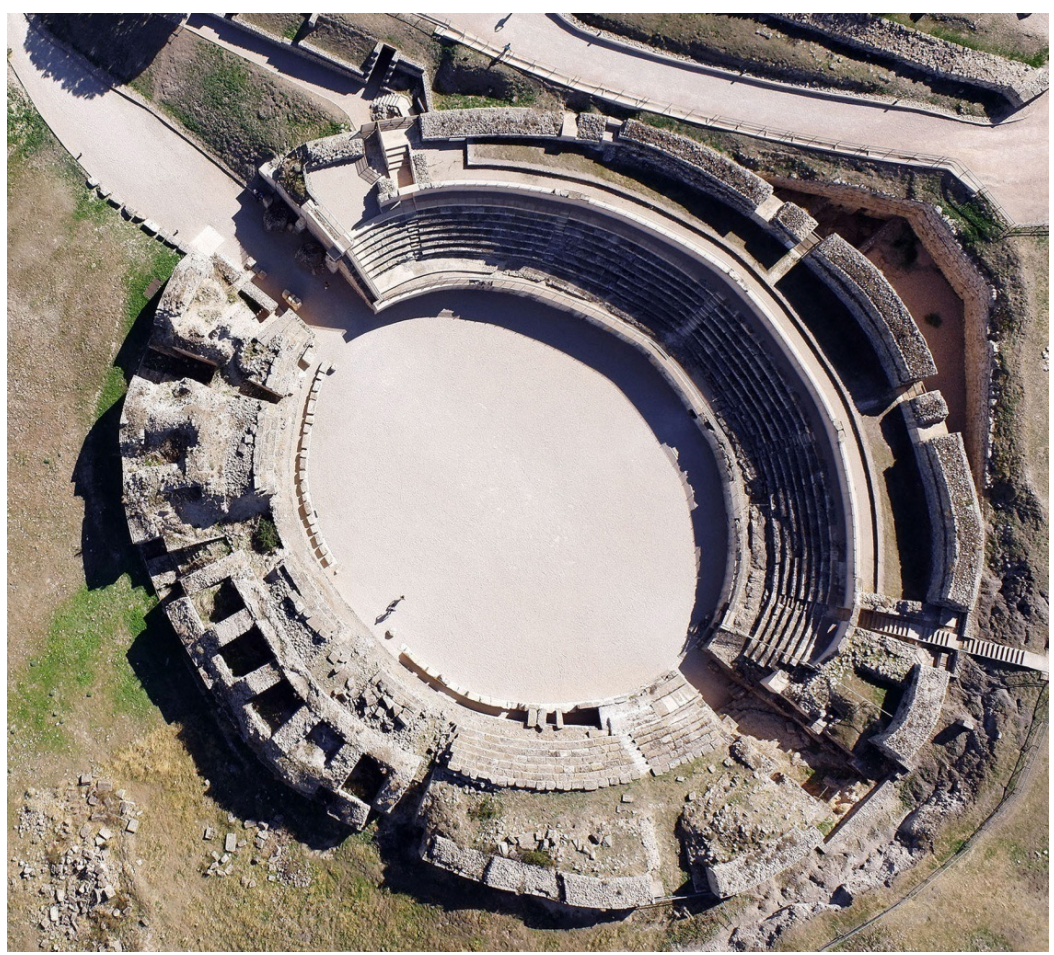

Fig. 7. Vista aérea del anfiteatro de Segobriga. Imagen tomada con dron el 8 de octubre de 2019 (C) J. Miranda).

El podium está constituido en el graderío norte por un alto muro de sillares $\mathrm{y}$, en gran parte de la zona sur, por la propia roca tallada, coronado en todo caso por una moldura que delimitaba a su vez la primera praecinctio de la gradería. Una galería perimetral junto al podium norte, cubierta por grandes losas de piedra, unía las dos puertas que daban acceso a la arena. La situada al este o porta triumphalis presenta dos tramos de bóvedas soportadas por tres arcos y conserva las huellas de su umbral, que permiten restituir una puerta de dos hojas y otra más pequeña de acceso al corredor de servicio. La Puerta Oeste, que también fue cubierta mediante bóvedas, dispone de una escalera muy empinada tallada en la roca y muestra evidencias de haber sido cerrada mediante una única hoja. Junto a ambas, en su lado septentrional, se situaron dos carceres abovedadas de tamaño parecido, la oriental abierta al corredor adintelado de servicio y la occidental comunicada directamente con la Puerta Oeste. Otras dos pequeñas habitaciones se situaron asimismo al nivel de la arena, una en el extremo norte del eje menor y otra en el podio sur, coincidiendo con el eje del $4^{\mathrm{o}}$ cuneus.$^{54} \mathrm{La}$ del lado sur, que está excavada en la roca, mide $2,75 \times 2,00$ $\mathrm{m}$ y cuenta con un acceso adintelado y una bóveda interior; debe vincularse con el sistema de evacuación de las aguas de lluvia del edificio al estar unida al canal de desagüe que atraviesa la arena en dirección este-oeste. La funcionalidad de la otra, situada en el lado norte, abierta al corredor de servicio, abovedada y de 2,50 x 2,35 $\mathrm{m}$, resulta aún incierta.

$54 \quad$ Almagro Basch 1984a, 74. 
La gradería del anfiteatro de Segobriga se divide en dos maeniana, la imma y la summa cavea, que quedan separadas por el muro del balteus. Los asientos de la imma cavea eran de piedra, mientras que los de la parte superior fueron de madera, como intuyó Fernández. ${ }^{55}$ El espacio entre el muro del balteus y la fachada sur del anfiteatro se terraplenó con un relleno constructivo muy homogéneo que generó una plataforma maciza a cota de apoyo de la pieza moldurada de remate del balteus. Sobre ella debió de descansar el armazón de las gradas de madera, cuyas vigas apoyaron además en sendos estribos corridos existentes en la cara interna del anillo exterior del anfiteatro. La ausencia de cualquier evidencia de cimentaciones u otras estructuras que puedan relacionarse con gradas de sillería corrobora esta propuesta, que no resulta inusual en la arquitectura de este tipo de edificios. Sus antecedentes más remotos se remontan a época tardorrepublicana, a aquellas estructuras temporales -teatros, spectacula - levantadas en madera para la celebración de ludi y munera gladiatoria como consecuencia de las prohibiciones decretadas contra los edificios permanentes de espectáculos en la ciudad de Roma. ${ }^{56}$ En edificios estables suelen asociarse a terraplenes o estructuras macizas sobre las que se sostienen las armazones de madera que constituyen sus gradas, siendo frecuentes en construcciones republicanas, pero también usadas a lo largo de todo el siglo I d.C. e incluso aparejadas todavía en momentos posteriores. ${ }^{57}$

La imma cavea se iniciaba con un pasillo anular junto al podio de la arena. Tras él, una grada de honor y, a continuación, siete filas de gradas, la primera con reposapiés. Un segundo pasillo se situaba a la misma cota que la última fila de gradas y contiguo al muro del balteus. Cinco escaleras radiales permitían comunicar ambas praecinctiones y dividían la gradería en seis cunei. Una estructura de sillares localizada en el centro del $4^{\circ}$ cuneus, ocupando toda la grada de honor y sobre la pequeña estancia abovedada accesible desde la arena, permite plantear la existencia de asientos privilegiados, probablemente un palco reservado al presidente o al editor de los juegos. Su disposición remite a otros ejemplos de pulvinar o suggestum, aunque en el caso segobrigense debió de carecer de elementos ornamentales dado su carácter prioritariamente funcional ${ }^{58}$ (Fig. 8).

La cronología del anfiteatro fue determinada en un primer momento en época claudio-neroniana, pero fijada con posterioridad en época tiberiana para el inicio de las obras y época vespasianea para su conclusión. ${ }^{59}$ La intervención arqueológica realizada entre los años 2011 y 2013 confirmó la fecha del 70 d.C. para la construcción de, al menos, la gradería sur gracias a la excavación de un vertido de nivelación existente al sur del edificio, de más de $900 \mathrm{~m}^{3}$ de rellenos de tierra de distinta composición y procedencia, deliberado y coetáneo a la edificación de su anillo exterior, que sirvió para cegar el espacio vacío comprendido entre la antigua muralla y el muro de fachada del anfiteatro. ${ }^{60} \mathrm{El}$ aforo original del edificio ha sido establecido en torno a 5.500 espectadores. ${ }^{61}$

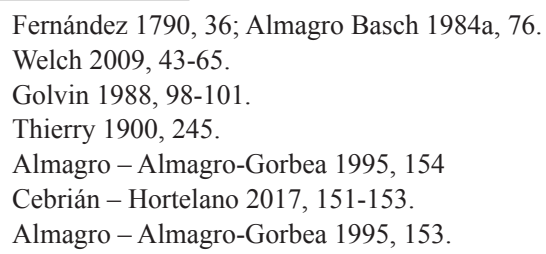




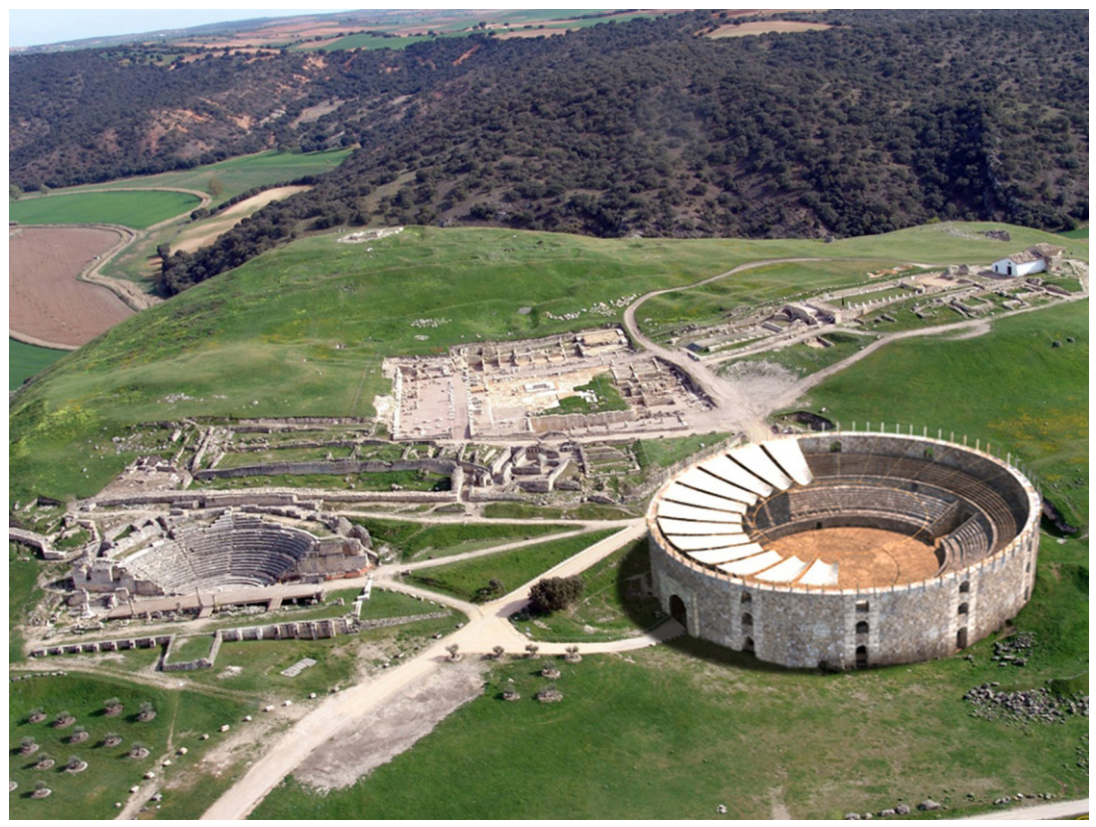

Fig. 8. Propuesta de restitución del anfiteatro de Segobriga montada sobre una imagen aérea desde el norte del yacimiento arqueológico (imagen creada por Balawat a partir de los datos arqueológicos proporcionados por el equipo de investigación).

\section{Referencias bibliográficas}

Abascal, J. M. (2014): “Juan Antonio Fernández (1752-1814), el epigrafista accidental”, Habis 45, 187-206 (http://dx.doi.org/10.12795/Habis.2014.145.10).

Abascal, J. M - Alberola, A. - Cebrián, R. - Hortelano, I. (2010): Segóbriga 2009. Resumen de las intervenciones arqueológicas, Cuenca.

Abascal, J. M. - Cebrián, R.

(2006a): "La inscripción métrica del obispo Sefronius de Segobriga (IHC $165+398$; ICERV 276). Una revisión cronológica”, [en] E. Conde - R. González Fernández - A. Egea (eds.), Espacio y tiempo en la percepción de la Antigüedad Tardía, Homenaje a Antonino González Blanco (=Antigüedad y Cristianismo 23), Murcia, 283-294.

(2006b): Manuscritos sobre Antigüedades de la Real Academia de la Historia (=Real Academia de la Historia. Publicaciones del Gabinete de Antigüedades. Antiquaria Hispanica 12), Madrid.

(2009): Los viajes de José Cornide por España y Portugal de 1754 a 1801 (=Real Academia de la Historia. Publicaciones del Gabinete de Antigüedades. Antiquaria Hispanica 19), Madrid.

Alföldy, G. (1987): Römisches Städtewesen auf der neukastilischen Hochebene. Ein Testfall für die Romanisierung, Heidelberg.

Almagro Basch, M.

(1943): "La colaboración de la aviación española en el campo de la Arqueología", Ampurias 5, 247-249. 
(1983): Segobriga I. Los textos de la antigüedad sobre Segobriga y las discusiones acerca de la situación geográfica de aquella ciudad (=Excavaciones Arqueológicas en España 123), Madrid.

(1984a): Segóbriga. Guía del Conjunto Arqueológico, Madrid.

(1984b): Segobriga II. Inscripciones ibéricas, latinas paganas y latinas cristianas (=Excavaciones Arqueológicas en España 127), Madrid.

Almagro, A. - Almagro-Gorbea, M.

(1995): "El anfiteatro de Segobriga", [en] Bimilenario del anfiteatro romano de Mérida. Coloquio internacional El anfiteatro en la Hispania romana (Mérida 26-28 de noviembre 1992), Mérida, 139-176.

(1997): “Análisis y reconstrucción del anfiteatro de Segobriga", [en] M. Almagro Gorbea (dir.), Ciudades romanas en la provincia de Cuenca, Homenaje a Francisco Suay Martínez (=Arqueología Conquense XIX), Cuenca, 69-91.

Almagro-Gorbea, M. (1990): "La urbanización augustea de Segóbriga", [en] W. Trillmich -

P. Zanker (eds.), Stadtbild und Ideologie. Die Monumentalisierung Hispanischer Städte zwischen Republik und Kaiserzeit. Kolloquium in Madrid (Oktober 1987), (=Bayerische Akademie der Wissenschaften, Philosophisch-Historische Klasse. Abhandlungen 103), München, 207-218.

Alsinet, J. (1888): "Ruinas romanas de Cabeza del Griego en 1765", Boletín de la Real Academia de la Historia 13, 353-355.

Capistrano de Moya, L. (1792): Noticia de las excavaciones de Cabeza del Griego, Alcalá de Henares.

Cebrián, R.

(2002): Comisión de Antigüedades de la Real Academia de la Historia: Antigüedades e inscripciones (1748-1845): catálogo e índices (=Real Academia de la Historia. Publicaciones del Gabinete de Antigüedades. Comisión de Antigüedades. Catálogos e índices IV.4), Madrid.

(2014): "Las excavaciones y estudios de Pelayo Quintero sobre Segobriga", [en] E. Gozalbes - M. J. Parodi - A. Ma Gálvez (coords.), Pelayo Quintero Atauri (1867-1946), el sabio de Uclés. Actas de las Jornadas (enero 2010, Cuenca), Cuenca, 131-156.

(2020): "Nuevos hallazgos epigráficos de Segobriga (2011-2017)", Cuadernos de Arqueología de la Universidad de Navarra 28, 167-192 (https://doi. org/10.15581/012.28.002).

Cebrián, R. - Hortelano, I. (2017): “Carrot amphorae y otras ánforas de origen sirio-palestino procedentes de un contexto vespasianeo de Segobriga (Saelices, Hispania Citerior)", SPAL 26, 151-185 (http://dx.doi.org/10.12795/spal.2017i26.07).

Cornide, J. (1799): "Noticia de las Antigüedades de Cabeza del Griego, reconocida de orden de la Real Academia de la Historia por Don Josef Cornide", Memorias de la Real Academia de la Historia II, 71-244.

Fernández, J. A. (1790): Noticia de la escabacion Hecha en el Territorio que llaman Cabeza del Griego, y sus descubrimientos, año de 1790, Real Academia de la Historia, Ms. 9-5597.

Golvin, J.-C. (1988): L'Amphithéâtre romain: Essai sur la théorisation de sa forme et de ses fonctions (=Publications du Centre Pierre Paris 18), Paris.

Maier, J. (2005): "II Centenario de la Real Cédula de 1803. La Real Academia de la Historia y el inicio de la legislación sobre el Patrimonio Arqueológico y Monumental de España", Boletín de la Real Academia de la Historia 200, 439-473.

Martínez Falero, J. F. (1805): “Impugnación al papel que con título de Munda y Cértima celtibéricas dio a luz el R. P. M. Fr. Manuel Risco, del Orden de S. Agustín remitida en 
27 de junio de 1802 a la Real Academia de la Historia por su individuo correspondiente D. Juan Francisco Martínez Falero, abogado de los Reales Consejos, vecino de la villa de Saelices", Memorias de la Real Academia de la Historia IV, 1-73.

Morales, A. de (1792 [1574]): Las antigüedades de las ciudades de España que van nombradas en la corónica con las averiguaciones de sus sitios y nombres antiguos, Madrid.

Quintero, P. (1913): Uclés. Excavaciones efectuadas en distintas épocas y noticia de algunas antigüedades, Cádiz.

Quintero, P. - Paris, P. (1902): “Antiquités de Cabeza del Griego”, Révue des Études Anciennes 4, 245-257 (https://doi.org/10.3406/rea.1902.1283).

Sánchez-Lafuente, J. (1995): “Algunos testimonios del uso y abandono de anfiteatros durante el Bajo Imperio en Hispania: el caso segobricense", [en] Bimilenario del anfiteatro romano de Mérida. Coloquio internacional El anfiteatro en la Hispania romana (Mérida 26-28 de noviembre 1992), Mérida, 177-183.

Sesiones 1837 = Cortes Constituyentes de la Nación Española. Diario Oficial de las sesiones de enero y febrero de 1837, tomos I y II, Madrid.

Thierry, C. (1900): “Amphitheatrum", [en] E. Daremberg - E. Saglio, Dictionnaire des Antiquités Grecques et Romaines, Paris, 241-247.

Welch, K. E. (2009): The Roman Amphitheatre. From its origins to the Colosseum, Cambridge. 